\title{
AC 2011-1621: MOODLE AS A COURSE MANAGEMENT SYSTEM IT ISN'T JUST FOR DISTANCE LEARNING
}

\section{Ronald H Rockland, New Jersey Institute of Technology}

Dr. RONALD H. ROCKLAND received his B.S.E.E. and M.S.E.E. in electrical engineering and a Ph.D. in bioengineering and electrical engineering from New York University in 1967, 1969 and 1972 respectively. He also received an M.B.A. in marketing from the University of St.Thomas in 1977.

He started his industrial career in Newark, NJ, establishing the biomedical engineering department at Newark Beth Israel Medical Center in 1970. He has almost 25 years of industrial experience in research, engineering, marketing and sales management and general management with several high technology corporations in the medical device and scientific instrumentation areas. Prior to joining New Jersey Institute of Technology (NJIT) in 1995 as an Assistant Professor in Engineering Technology, he was an adjunct professor in marketing for eight years with County College of Morris and Bergen Community College.

He is Chair and Professor of Engineering Technology at NJIT, with a joint appointment in Biomedical Engineering, and holds the designation of Master Teacher. Prior to that, since 2002, he was the Associate Dean for the Newark College of Engineering. Dr. Rockland has over 50 conference and journal publications in the area of engineering outreach to the K-12 community and in biomedical research, and holds 5 patents in the biomedical area.

\section{Howard S. Kimmel, New Jersey Institute of Technology}

Dr. Kimmel is Professor of Chemical Engineering at New Jersey Institute of Technology in Newark, NJ, and Associate Vice President for Academic Affairs. He has been Executive Driector for the Center for Pre-College Programs at NJIT for over 30 years. Dr. Kimmel has had numerous NSF grants and State grants focusing on professional development, curriculum, and assessment. In addition, he is a member of the assessment committee for Chemical Engineering.

\section{John D. Carpinelli, New Jersey Institute of Technology}

JOHN D. CARPINELLI is a Professor of Electrical and Computer Engineering and Director of the Center for Pre-College Programs at the New Jersey Institute of Technology. He has served as coordinator of activities at NJIT for the Gateway Engineering Education Coalition and as a member of the Coalition's Governing Board. He previously chaired NJIT's Excellence in Teaching Awards Committee and is past chair of the University Master Teacher Committee. 


\title{
Moodle as a Course Management System - It isn't just for Distance Learning
}

\begin{abstract}
Moodle, WebCT, Blackboard and Sakai are examples of course management systems that have been traditionally used for distance learning (DL) classes. In fact, the Moodle website (http://moodle.com/) states that "Moodle is a course management system designed to help educators who want to create quality online courses." Instructional delivery and the use of technology have changed over the years. Faculty need to identify effective strategies that could improve and strengthen academic programs in order to meet the learning needs of all students, especially the Net Generation students ${ }^{1}$.

While these systems have been used extensively for online courses, they can also provide a technological means to develop more effective teaching in a face to face environment. There have been instances where these systems have been used with both simultaneous face to face and distance delivery ${ }^{2}$, but this paper will focus on using these systems strictly for face to face classes.
\end{abstract}

One of these systems, Moodle, has been used for two years in three Electrical and Computer Engineering Technology courses at New Jersey Institute of Technology. Of the three courses, one is a senior design capstone project course, one is a traditional lecture course, and one is a combination of lecture and laboratory. This paper will describe the attributes of this course management system, and how it can be effectively incorporated into a face to face course. Some of the attributes that will be described in this paper include:

- Students can upload assignments, and be able to see their grade, comments from the instructor, and have their assignments stored

- Students can review their grades on all assignments and exams, and understand if there are missing assignments

- Students can be part of chat rooms (forum), even though the class is face to face

- Additional meetings with students, outside the normal class hours, can be accomplished through use of a product called Wimba, which is a collaborative learning software application that seamlessly works with Moodle

Specific examples of how these, and other attributes of this course management system were used in lecture, lab based and senior project Electrical and Computer Engineering Technology courses will be described, and how using this type of course management system can assist in transitioning a face to face course to either a hybrid format or a fully distance learning format.

Background on Moodle

Moodle (abbreviation for Modular Object-Oriented Dynamic Learning Environment) was developed by Peter Taylor ${ }^{3}$ in 2001, and was used to support social constructionist 
epistemologies of teaching and learning. Several years ago, the author's university switched its course management system from WebCT to Moodle. While Moodle is an open source program, an institution either needs to host this application on their server or use an outside service. Our university uses Moodlerooms (http://www.moodlerooms.com/) to host and support this application. Moodle is used worldwide, and currently there are 46,388 currently active sites that have registered for Moodle from 206 countries.

One of the main advantages of Moodle is its structure, which can either be a topic based or time (weekly) based, as opposed to a module based structure. There is a section before week 1 where general links, that are not dependent on a specific weekly assignment, can be placed.

The weekly structure allows an instructor to mirror his or her own syllabus for the course. Thus, each week is outlined in the Moodle page, along with links to information, uploads and grades. The time to develop the first Moodle page varies, but if you have a detailed syllabus, it should take approximately 2-3 hours to first populate the Moodle page. Instructors can then go back on insert additional resources, modify the grading scales, and modify the due dates.

The format in Moodle allows the instructor to organize a course with all the elements. Figure 1 below shows one week, and part of the top section, of the Moodle page for the Circuit 1 lecture/laboratory course. Note that each week is annotated with the reading assignments, topics, links to PowerPoints or other documents, and the ability to email the students.

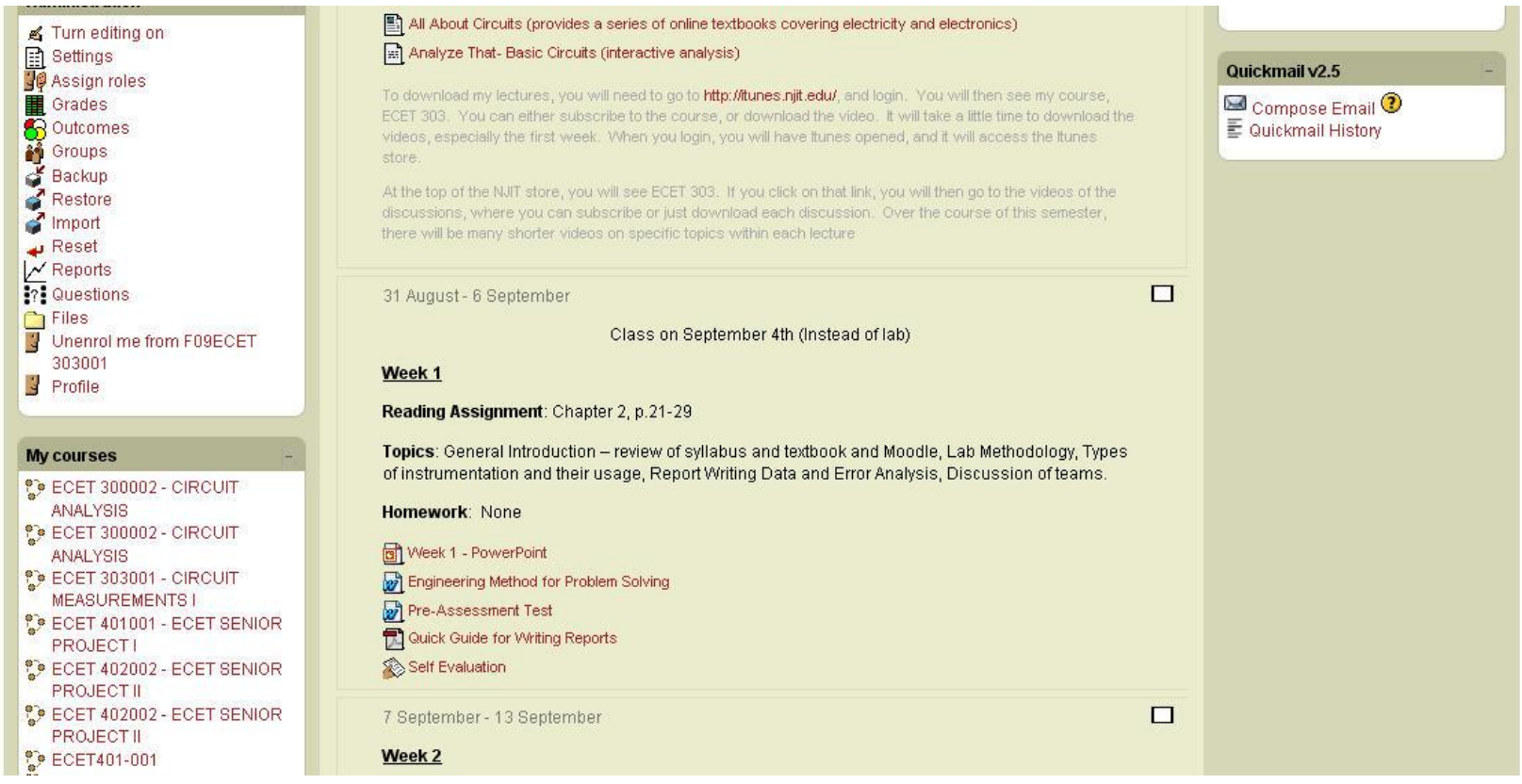

Figure 1. Example of part of the author's Moodle page for the lecture/laboratory course.

While many of the aspects of the Moodle page, such as posting assignments and syllabi, can be done through an instructor's personal webpage, there are many advantages of using the Moodle page, even if you used very few of its attributes. Once a Moodle webpage is completely filled in, with various resources or activities, it can be backed up and restored to the next semester. Thus, 
the instructor does not have to redo a webpage with new dates and information. In fact, the Moodle page should serve as a syllabus, and any information, such as office hours, class schedules, etc., can be put on the Moodle page rather than a separate syllabus. The author still uses a separate syllabus, but finds that most students look at the Moodle page to see what assignments need to be done.

There are a number of resources and activities that can be used in Moodle for distance learning classes, and this paper will concentrate on a few of those resources and activities that have been used in face to face classes. These include posting grade books, posting and uploading assignments, posting links, creating discussion forums, and using Wimba for virtual classroom discussion.

\section{Course Description}

Before discussing how Moodle was incorporated into a face to face class, it is important to understand what classes this system was used. The three courses that will be discussed in this paper are junior level and senior level Electrical and Computer Engineering Technology program (ECET) courses. The ECET program at the university was an upper two year program until recently, and one of the courses, Circuit Measurements, was the first course that the transfer students took. It consists of a one hour lecture and two hour laboratory, and typical topics in this course include Error Analysis, Ohm's, Kirchoff's Laws, Voltage and Current division, Independent and Dependent Sources, Mesh and Nodal Analysis, Thevenin/Norton, First Order Response and AC Steady State analysis.

The second course is an upper junior level course, similar to a Circuits II course, and includes topics such as Laplace Transform, Bode Analysis, Systems Analysis and Fourier Analysis. Unlike the first course, this course is a lecture only class.

The third course is the first semester of a senior design capstone course, where students develop a design for a microcontroller based product. The second semester of this course is used to complete the design and build and demonstrate the product.

All three courses have been taught by the instructor face to face, and the instructor has been teaching each course for over 10 years. Two years ago, the instructor first started using Moodle in these courses, and has modified the course Moodle pages, and their usage, since then. The next several sections will summarize some of the key aspects of Moodle, and how it can help both the instructor and the student in a face to face course.

\section{Overall Structure}

Because of the structure of the Moodle webpage, which can either be a weekly or topic oriented structure, students clearly can see the entire course outline, what is expected and will be covered each week. Also, the Moodle course page is tied into the registration system, so when you click on the main page, you can see the current participants (students). One of the problems many instructors have (including the author) is remembering student names, and one idea is to take a 
picture and put the name next to the picture. Moodle allows students to put a user picture next to their name. This way, the students are helping the instructor with name recognition.

\section{Resources for students}

It is very easy to insert, in the proper week, resources such as websites, documents or other files. Before the first week section there is a section where resources that are not week oriented can be inserted, such as a syllabus or a lab manual. In prior years, the author used his own web page to upload this information, and had to develop methods to make sure that some of this information was available to only the students enrolled in that course. Since a Moodle class webpage can only be viewed by first logging in with a proper username and password, the information on the Moodle webpage is restricted to the students in the class. If a student is dropped from the class (or withdraws from the class) then access to this material is restricted.

Another aspect to access by participants (which is what teachers and registered students are called), is that the instructor can add additional people to view the Moodle page, and assign them different roles, such as a non-editing teacher, who can grade an assignment but not add any new resources. For one of the assignments in the senior project class, one of the research librarians wanted the ability to view them and grade them. That was very easy in Moodle. Otherwise, the instructor would have to collect the assignments, send them to the librarian, have the librarian grade them, send it back to the instructor, who would then hand it back to the students.

Because the Moodle course page is tied to the registration, instructors can use the email feature to email to all or part of the class. It is the most direct way to email to students in a class.

Assignments and Grading

In Moodle, students can upload assignments to the specific week by simply creating what is called an activity. For the senior project class, all assignments are uploaded directly to Moodle (similar to distance learning class) and grades and comments are posted for the students. For the laboratory based course, all lab reports are uploaded to the Moodle page. For the lecture only class, some of the assignments are uploaded directly to Moodle.

However, any assignment involving extensive calculations are usually hand written by the students. For a distance learning class, they would need to be scanned and uploaded. Currently, for any of the three classes described in this paper, students aren't required to scan their work. Instead, there is another assignment resource that allows the instructor to just post the grade, as well as any comment, and grade the assignments that were handed in on paper. That is the same concept that can be used for tests, quizzes, or any other student work where it cannot be uploaded to the web.

One of the weaknesses in the current version of Moodle is the space box given for comments - it is very restrictive. An alternative to that is for the instructor to download the assignment and use Track changes to make comments. A separate resource can be used for the corrected paper, or the instructor can simply email the corrected paper to the student (or in the case of the senior project, a group of students who had to submit a preliminary write-up). 
Since all the assignments are uploaded in the senior design capstone course, the instructor has one site containing all the student work, which can be very useful when gathering material for accreditation. There is no need to create folders on the instructor's computer, or to copy these files to a home computer. Access is universal - the instructor does not need his or her computer to access these assignments. Instead, all you need is to log into your Moodle page, which would have all the classes you are teaching utilizing Moodle.

There is one clear advantage for students - they know what assignments have been graded, and what assignments, at least according to the instructor, has not been submitted. A greater number of assignments have been submitted since the author started using Moodle in his face to face classes. Also, students have a better idea as to what to expect for a final grade. To make it most efficient, instructors should weight each assignment based on their own scoring system.

\section{Forums}

This is a key feature for a DL class, but can be useful for face to face classes. The author has primarily used this feature in his senior design capstone class. Prior to using Moodle, students used to email questions, which the author would then respond to, and in some cases email the entire class. For the senior project class, students who have questions on microcontrollers, programming and other issues start individual forums, and other students were encouraged to participate in these forums with their own comments. These forums are monitored by the instructor. For the Fall 2011 semester, the author will expand this ability to the lecture/lab class, and can restrict the forum use to teams rather than the entire class.

\section{Review Sessions and Wimba}

Each class utilizing Moodle can also create a Wimba Classroom. This application creates a live, virtual classroom environment that includes audio and video. All students need to do to $\log$ in is to have Moodle, while an instructor should also have access to a tablet. Last year, for the classroom only course, a test was postponed until after the spring break. The only time to have a review session was during the spring break, and rather than require students to come into school, the author ran a two hour review session using Wimba and a tablet. This session was also recorded using Camtasia Relay ${ }^{4}$, and posted for future reference. Students were able to ask questions, and the author was able to write solutions on the tablet. All but two students attended this virtual review session, and based on the number of questions, they enjoyed it. The students were at their homes, while the instructor was in a classroom (although for future Wimba use, the instructor can be home as well). This semester, rather than trying to schedule classrooms for off time review sessions, all review sessions will be Wimba based.

\section{Feedback from students}

Although no formal survey has been given to the students (one is currently being developed for the spring semester), students have commented favorably to the use of Moodle. Students especially liked the ability to see their grades, as well as to upload their assignments. 


\section{Transitioning to Hybrid or Complete Distance Learning}

To offer students a more versatile schedule, there is a growing need to create hybrid (face to face one week/DL one week) or full DL courses. By slowly populating a Moodle page with a variety of links, videos, references, as well as dealing with student work product online, instructors can easily transition non-lab based courses to either a hybrid mode or full DL mode. The author is considering a hybrid version for the senior design capstone course, and is looking at a National Instruments product to incorporate into a hybrid or fully DL version of the lecture/laboratory course.

\section{Conclusion}

Course management systems, such as Moodle, have enabled courses to be effectively delivered in an online format. The features that these systems have can also be effective in a face to face classroom, helping both the instructor and the student. This paper has shown several of these features used in a variety of face to face classes, including laboratory based, lecture based, and a senior capstone design course.

\section{References}

[1] Kyei-Blankson, L., Keengwe, J., Blankson, J. "Faculty Use and Integration of Technology in Higher Education”, AACE Journal, v17 n3 p199-213 Jul 2009

[2] White, C.P., Ramirez, R., Smith, Jessica G., Plonowski, L. "Simultaneous Delivery of a Face-to-Face Course to On-Campus and Remote Off-Campus Students" TechTrends v. 54 no. 4 (July 2010) p. 34-40

[3] Dougiamas, M.; Taylor, P. "Interpretive analysis of an internet-based course constructed using a new courseware tool called Moodle", Proceedings of HERSDA 2002 Conference, July 2002, Perth, Western Australia

[4] Rockland, R., Kimmel, K., Hirsch, L, Carpinelli, J., Burr-Alexander, L. "Technology and Learning Objects in the Engineering Technology Classroom”, Proceedings of the 2010 ASEE Annual Conference, Nashville, TN, June. 